\title{
Gender-Related Variability in Information Processing of Disclosure Documents
}

\author{
M. G. Ceravolo ${ }^{1} \cdot$ V. Farina ${ }^{2} \cdot$ L. Fattobene ${ }^{2}$ (D) $\cdot$ L. Leonelli $^{2} \cdot$ G. Raggetti ${ }^{3}$
}

Received: 8 June 2020 / Accepted: 18 January 2021 / Published online: 25 March 2021

(C) The Author(s) 2021, corrected publication 2021

\begin{abstract}
Disclosure is used worldwide as a tool to increase transparency and help investors to make their decisions, thus partially overcoming asymmetric information in financial markets. This research seeks to explore gender-related variability in visual attention allocation to the Key Investor Information Document, and in the evaluation of product financial attractiveness. The study exploits the eye-tracking methodology to collect neural data, responding to the call for considering new data sources. The analysis shows that men tend to dedicate more attention to the sections Objectives and Past performance while women spend more time to scan the sections Risk-reward profile and Costs and charges; When evaluating product financial attractiveness, women tend to evaluate them as poorly financially attractive more often than men. Results reveal the existence of gender-related variability in the visual search strategy for relevant information, which, in turn, can impact on the phase of product evaluation. These findings highlight the professional responsibility of regulators and supervisors to monitor sellers and marketers' behaviours when they interact with consumers. Moreover, this study could provide support to develop financial disclosure documents considering individual differences and ensuring that adequate attention is allocated by investors to all financial information sources, thus raising the level of investor protection. Eventually, the study stimulates innovations to be embedded in the world-wide ongoing regulatory developments that aim at increasing transparency requirements.
\end{abstract}

Keywords Investor protection $\cdot$ Attention $\cdot$ Disclosure $\cdot$ Gender $\cdot$ Information $\cdot$ Eye tracking

\section{Introduction}

A crucial component of investor protection policy in financial services is disclosure (Durkin and Elliehausen 2011). Already back in 1968, the United States Congress passed acts that

\section{Fattobene}

lucrezia.fattobene@uniroma2.it

Extended author information available on the last page of the article 
required lenders to provide consumers with disclosure information about terms and rates for different products such as mortgages, credit cards, or other consumer loans. Over time and worldwide, several laws featuring consumer disclosures as a central element have been approved, and acknowledging the relevance of protecting and informing investors, many consumer testing programmes to craft effective disclosures have been launched by authorities such as the Consumer Financial Protection Bureau in the United States of America (USA), the Financial Services Authority in the United Kingdom (UK), and the Financial Consumer Agency in Canada. The European Commission has recently introduced a short and consumer friendly disclosure document for mutual funds (Undertakings for Collective Investment in Transferable Securities - UCITS products), the Key Investor Information Document (KIID), which is aimed at providing investors with all the basic relevant information to take their investment decisions.

The underlying idea in drafting disclosure documents is that the reduction of investors' information load facilitates the cognitive process of paying attention to it, improving the reading and the understanding of the product key characteristics. Information about financial products can be difficult to process, and in the wake of the last financial crisis, concerns about the complexity of financial information provided to investors have heightened (Buchanan 2016; Schoen 2017). Nonetheless, research activities are failing in considering factors which affect consumer decisions below the awareness level (Chowdhury 2019). The role of automatic and unconscious factors in modulating behaviour is explored in advertising research, labelling research and food choice (Bauer and Reisch 2019; Marette et al. 2019; Ní Choisdealbha and Lunn 2020), and environmental policy (Ölander and Thøgersen 2014). Surprisingly, despite the acknowledgment that financial consumers neither gather nor process information as expected by the homo oeconomicus paradigm (Oehler and Wendt 2016), little research is conducted to understand the automatic mechanisms at the basis of financial information processing. There is no evidence on how authorities should discipline disclosure communications to improve investors' data processing, which is a crucial phase in investors' decision-making. Research on disclosure documents in the financial industry has extensively shown the need to improve the way these documents are crafted, and a call for new methods and new data sources has been launched (Hogarth and Merry 2011; Hung et al. 2015). We aim at answering this call for new approaches to study investors' protection and disclosure information, by investigating the very early phase of visual data search, recording it by means of eye tracking.

Previous literature has detected several individual-level factors which affect households' financial behaviour such as investor-advisor similarity in personality traits (Zubair Tauni et al. 2020), the feeling of being competent (Graham et al. 2009), psychological factors as locus of control, copying styles (McNair et al. 2016), self-control, optimism, and deliberative thinking (Strömbäck et al. 2017), and financial literacy and financial numeracy (Almenberg and Dreber 2015; Lusardi and Mitchell 2008). Recently, neurofinance, applying different neuroscientific methodologies in order to investigate subjects' brain and neurophysiological mechanisms which drive decision outcomes, has started to underpin the need to unravel the biological basis of the individual differences, paying special attention to gender-related variability in financial behaviour (Miendlarzewska et al. 2017). The economics, psychology, and sociology literature have largely documented the existence of a gender gap in financial participation and decision-making, highlighting that males are more often primary decision-makers when dealing with savings and investment decisions (Boggio et al. 2020). Women have been found to participate less in trading activities, own and manage less personal and family wealth, own less risky portfolios, and prefer to invest their financial resources more prudently than men (Bucher-Koenen et al. 2016). At the same time, results from experimental asset markets 
suggest that a mixed-gender composition in the financial industry could reduce mispricing and foster stability, making the increase of the fraction of women negotiating in financial markets highly desirable (Cueva and Rustichini 2015). Studies on gender differences based on surveys and experiments thus provided the researchers with some elements to develop the Lehman Sisters hypothesis, which, while refusing the idea that a women-dominated financial market would be more stable, states that gender imbalances in the financial sector exacerbate instability and more gender mix could be helpful (van Staveren 2014). Using the eyetracking methodology, we sought to investigate whether a gender-related variability exists in the initial phases of financial information processing and to assess the possible effects on product evaluation.

The topic of gender differences is among the most widely discussed and continues to attract widespread interest for different reasons. First, even if people do not support gender stereotypes, their diffusion could have self-fulfilling effects through their impact on judgment and behaviour (Fine 2012). Second, there is considerable observed gender disparity in important economic and social contexts such as education, wages, labour market, and prospect for advancement. Finally, given that gender is invoked in many policy issues, it is important to collect, organize, and interpret data in a scientific way (Hyde 2014). We therefore wish to contribute to fill the gap in the research on how investors process financial information, using a neuroscientific method to measure the initial phase of information processing. Confirming the cliché according to which oculus animi index, neuroscientists use to say "the eye is a window to the brain" (London et al. 2013), and in fact, research into oculomotor behaviour indicates a close relationship between eye movements and attention as an automatic mechanism for visual stimuli selection (Ashby et al. 2016). Since attention allocation mostly occurs unconsciously, eye tracking can provide more reliable and accurate evidence of information processing than self-reported measures (Graham and Jeffery 2012; Orquin 2014; Vraga et al. 2016). On these premises, we endorsed the unobtrusive methodology of eye tracking to investigate financial consumer behaviour in the information collection phase, to understand whether gender influences attention allocation and evaluation of real KIIDs.

Results reveal that, in the search for relevant information, before rating the products as financially attractive or not, men tend to dedicate more attention to the narrative part of the document and to the Past performance while women spend more time to scan the sections Risk-reward profile and Costs and charges. When evaluating product financial attractiveness, women tend to evaluate them as poorly financially attractive more often than men.

Our contributions to the literature are manifold. Firstly, we advanced research by studying gender-related variability in the visual processing of financial information contained in disclosure documents, exploring one of the first phases of the decision-making process. Secondly, the neurofinance experimental protocol highlights the possibility to couple the studies for regulatory reforms in the field of investor protection with the study of the physiological mechanisms underlying the reading of disclosure documents, objectively measuring the process of attention allocation. Finally, while previous studies focused on formal laboratory tests, we analysed these differences, even if in a fictitious scenario, during a task that is based on real financial documents displaying real financial information.

The remainder of the paper continues as follows: Section 2 presents the literature review, focusing on consumers' protection and disclosure and on gender differences in financial behaviour, Section 3 reports the method, Section 4 illustrates the results and the discussion is provided in Section 5 . 


\section{Literature Review}

The asymmetric information which characterizes the financial services market, where providers have more information than consumers about risks, features, charges, and quality of the products and services, has led to the development of the policy tool of the disclosure, with the aim to increase transparency and provide investors with useful information to take decisions. Thus, worldwide, disclosure has become a crucial component of regulatory regime in financial markets and in different financial service industries - mortgages, credit cards, and mutual funds - regulation has focused on simplifying disclosure.

In USA, with respect to consumer mortgages, different disclosure documents were introduced to increase transparency about key terms and costs, and modified over time to improve borrowers' understanding and facilitate comparison. The need to improve the design of the documents was supported by empirical evidence showing that key terms in the disclosure documents were not understood by mortgage borrowers (Lacko and Pappalardo 2007, 2010). Starting from March 2016, a directive on the mortgage credit was implemented also in Europe (Mortgage Credit Directive 2014/17/EU), imposing information duties on the sellers through the European Standardized Information Sheet.

The design of disclosure documents is crucial also with respect to credit card since studies show that changes in the disclosure impact on borrowing behaviour (Poddar et al. 2014; Soll et al. 2013). The goal to protect consumers from information overload and unfair practices has recently been pursued in the USA by enhancing the disclosure of costs and penalties for credit card users through the approval of the CARD Act 2009, and, in Europe, by the EU Consumer Credit Directive that requests creditors and credit intermediaries to provide consumers with the Standard European Consumer Credit Information.

Finally, a further segment in the financial services industry where disclosure plays a crucial role as regulatory tool is that of mutual funds. In 2007, authorities introduced some rules to compose a summary document that improving investors' ability to make informed decisions should increase the competitiveness and efficiency of the US capital markets (SEC 2007). The guidance on the drafting of the Summary Prospectus was recently updated to reduce the cases "in which disclosure remains complex, technical and duplicative" (SEC 2014). In order to do so, the new rules enhance the use of plain English, the focus on key information, and proposes to avoid cross-references. With respect to European investors' protection in the mutual fund industry, the European Commission introduced the KIID for UCITS products, replacing the Simplified Prospectus (SP). Surveys, telephone interviews, and focus groups, both on investors and intermediaries, were conducted to achieve the final standardized template ${ }^{1}$. Investigating the efficacy of this prospectus, Walther (2015) observes that the KIID performs better than the replaced SP, and that it exposes investors to less information overload. The document has not been considered fully appropriate in conveying basic information, as highlighted by the study of Oehler et al. (2014) who reveal the need to keep improving the disclosure format.

Overall, empirical evidence and surveys of the academic literature on consumer disclosure in the financial industry reveal that even if there has been a considerable effort by regulators in reducing the abundance and the complexity of disclosure documents, additional studies are needed to evaluate how to draft them, and in particular, new methods have to be exploited to collect more diversified data. In this perspective, we propose to focus on a specific disclosure document among the different mentioned, the KIID, by applying a new method. Recently, the

${ }^{1}$ The template is provided in the CESR/10-794 consultation paper. 
eye tracking has been introduced in the study of financial decision-making because it provides new information about brain functions. Given that many studies have been conducted on disclosure information through standard methodologies but no research from neurofinance is available on the topic, we propose to start the investigation by deepening the link between attention towards financial information and one specific investor's characteristic: the gender.

A standard assumption in several traditional finance models is the homogeneous and standardized use of information by investors. On the contrary, the selectivity model by Meyers-Levy (1989) has highlighted gender differences in information processing, proposing that men and women select different cues when processing information and that, in particular, men tend to be selective, details insensitive, and heuristic-based processors, while women engage in comprehensive and effortful processing of all available information. The extension of this model to the realm of financial decisions, i.e., if men and women interact with financial information in different ways, has implications for those interested in drafting the documents that convey disclosure information. Different information processing might be associated with different perception of the underlying financial product or service and this, in turn, can lead to different financial choices. Previous studies provide evidence of gender-related variability in different households' financial behaviours such as savings (Fisher 2010), keeping to a budget (Hayhoe et al. 2000), and retirement preparation (Lyons et al. 2008). Women have been found to trade less (Barber and Odean 2001; Barclays Wealth 2011), weight risk attributes more (Olsen and Cox 2001), prefer risk-free assets (Hariharan et al. 2000), diversify their portfolios more (Vanguard Retirement Centre Research 2011), choose safer investment mix to compose their portfolios (Jianakoplos and Bernasek 1998), and more fixed-income investment alternatives (Bajtelsmit and VanDerhei 1997), than their men counterparts. Empirical research reveals that women feel more anxiety related to financial matters, and often conforming to their husbands' choices generally does not participate in household financial decision making (Dema-Moreno 2009; Yilmazer and Lyons 2010).

Although these investigations offer meaningful insights into financial decisions across gender types, surprisingly, to date no studies have investigated gender-related variability in the early phase of information processing of financial information and the relationship with financial product attractiveness evaluations. To fill this gap, the present research is carried out applying the eye-tracking methodology to the standardized financial disclosure document of the KIID, where new requirements have been recently introduced in order to provide investors with homogeneous basic information to make decisions. Specifically, we opted for this neuroscientific approach because of the tight link between attention and eye movements and since eye-tracking measures have been found to be more accurate and reliable than selfreported ones also in the case of observational behaviour: indeed, actual view differs from claimed view (O'Connell et al. 2011). This new methodology permits detecting where and at what subjects look (and do not look) and for how long, thus representing the most effective and widely employed tool to study visual attention allocation mechanisms.

\section{Method}

\section{Participants}

Thirty-six students at a major university voluntarily participated in this study. They were given a brief introduction about eye-tracking data recording and were informed about their rights and 
the experimental procedure; All of them gave their written informed consent to the study. The study received ethical approval from the local ethics Committee.

Out of the thirty-six participants in the sample, eighteen were men; seventeen were undergraduate students at the School of Medicine (eight men), while nineteen were undergraduate students at the School of Economics (ten men). The mean age was 25 years $( \pm 3)$. All the participants had normal or corrected to normal vision.

Subjects have been selected to compose a homogeneous sample of nonprofessional investors; Thus, we tried to control for some of the different variables which have been proved to affect attention and behaviours. We surveyed subjects in order to ascertain that they did not earn their own income, they did not play lottery scratch more than once a month, they did not participate to prior experiments involving investments or to any investment simulation, and they were not gamblers (casino, cards, slot machines). Moreover, we ascertained that subjects did not have any financial experience in the investment activity (i.e., they do not buy and sell securities such as bonds, stocks, mutual funds, and exchange traded funds). Students from both the Faculties successfully passed one exam of Math and one exam of Basic Statistics, and they did not attend any advanced course in those subjects. The majority of men of the sample declared that they used to play video games often (more than four times a week) when they were under sixteen and that they still played video games at the time of the experiment sometimes (more than twice a month). On the contrary, the majority of women declared that they used to play video games sometimes when they were under 16 and rarely (less than twice a month) at the time of the experiment. These inclusion criteria allowed ensuring a homogenous sample of students, more similarly naïve in investment behaviour.

\section{Eye-Tracking Device}

Eye movements were recorded using the SMI REDn Scientific (SensoMotoric Instruments $\mathrm{GmBH}$, Berlin, Germany) system, contact-free eye tracking that allows head movement compensation. The sampling rate was $60 \mathrm{~Hz}$. The system has a spatial resolution of $0.05^{\circ}$ and a gaze position accuracy of $0.4^{\circ}$. Participants were seated at a distance of $60-80 \mathrm{~cm}$ from the 15.6" laptop (screen resolution: $1366 \times 768$; grey background). Before each test, the device was calibrated using the software's 5-point monitor calibration. SMI REDn Scientific is also highly robust for vision corrections (glasses and contact lenses). ${ }^{2}$

\section{Task and Procedure}

The structure of the KIIDs used in this study follows the UCITS directive and consists of the following sections: (i) investment Objectives and policy, (ii) Risk-reward profile (RRP), (iii) Costs and charges, and (iv) Past performance. The fifth section established by the directivepractical information - has been excluded since it discloses the name of the financial institution offering the product. Such information is associated with the institution's image and reputation that, in turn, can elicit affective reactions and modulate the perception of the attractiveness of the product. In order to provide standard documents and ensure scientific validity, different precautions have been taken. In more detail, the stimulus background is white, the information is written in black with a constant font size of twelve, and the graphical

\footnotetext{
${ }^{2}$ The laboratory setting and the eye-tracking approach meet all the common requirements of using this method. For more information about the large set of requirements, please see Holmqvist et al. (2011).
} 
elements are in grey. This is to avoid the influence of colours on judgment and decisionmaking. In all the sections, the number of text lines is always the same across different stimuli to ensure comparison of eye tracking variables across the trials. The time period to which past performance is referred always consists of 10 years, ranging between 2007 and 2016. A constant time span ensures that people do not infer other information (i.e., if past performances are presented up to 2013, subjects can deduce that the fund is not profitable and not present on the market any longer, thus lowering the perceived attractiveness). In the seven-point scale of the RRP indicator, the classes 1 and 7 have never been selected to avoid anchoring effect driven by extreme values.

The study protocol implies the presentation of twenty-four consecutive slides, displaying as many different KIIDs, for a maximum of sixty seconds each, for a total number of 864 observations, in thirty-six subjects. Participants are allowed to move to the next trial by simply pressing the space bar as soon as they feel ready to rate the attractiveness of the product. The possibility to go forward is given to ensure that the subjects' eyes do not wander while waiting for the following stimulus. After the stimulus presentation, the task consists of rating the product as "Low," "Medium," or "High" financially attractive, using the laptop mousepad. In order to build the most ecological protocol possible, we added a task - the product evaluationthat was supposed to enhance subjects' motivation to process the visual information. However, we wanted to avoid hypothetical choices about financial product purchase as students do not have a personal income and the decision of buying the products, or not, would have been influenced by several variables, whose investigation was beyond the scope of the present research. During the explanation of the general procedure, subjects were instructed to evaluate each product in regard to the general attractiveness, thus providing their first impression after each visual stimulus. The time constraint for the visual exploration of the stimulus and a task about the attractiveness perception permit the experimenters to better capture subjects' gut feelings rather than involving them in the complex decision making process of purchasing (or not) the product, even if in a fictitious scenario. Before each trial, a fixation cross appears on the centre of the display and the trial starts automatically if the participant fixates on the fixation cross (approximately $1 \mathrm{~cm} \times 1 \mathrm{~cm}$ ) for at least 500 milliseconds (ms). This is to ensure that every participant would be looking at the centre of the stimulus display at the beginning of the trial. The scheme of the experimental procedure and an example of the standard stimulus presented to the subjects are displayed in Ceravolo et al. (2019).

\section{Outcome Measures}

The eye-tracking analysis (BeGaze software) allows the extrapolation of several quantitative variables describing the spatial and temporal parameters of gaze. Moreover, it is possible to divide the presented stimulus into different areas of interest (AOIs) in order to better understand the influence of different features of visual information on attention allocation. We chose to divide each slide into four AOIs corresponding to the four KIID sections. We also identified minor AOIs that are the years of the financial crisis (2007-2009), more recent years (20142016), the Risk scale ranging from 1 to 7 and the Disclaimer, which alert that past performances are not predictive of future returns.

We analysed the following gaze features:

- Time to first fixation: expresses the average interval (ms) from the presentation of the KIID document (start of the trial) to the first gaze fixation on each area of interest (AOI), 
averaged, for each AOI, across the visual stimuli. It represents a proxy of the relevance of information for the individual subject and allows tracking the scan path ${ }^{3}$ that is the sequence by which the document is visually scanned by each subject and usually the order in which visual stimuli are processed in the brain (Noton and Stark, 1971; Zhou et al. 2016).

- Net dwell time (NDT): represents the sum of net dwell time (ms) of all subjects divided by the number of subjects, averaged across the visual stimuli.

- Net dwell time percentage (NDT\%): represents the net dwell time (ms) divided by the difference between the end time and start time of each trial, averaged across all subjects and the visual stimuli. This parameter expresses the proportion of time spent to process each AOI, relative to the time spent to process the whole visual stimulus.

- Fixation count (FC): is the average number of fixations inside the AOI, i.e., the average number of times subjects spent a minimum of $200 \mathrm{~ms}$ looking at the AOI, averaged across subjects and the twety-four visual stimuli.

- Normalized dwell time (ms/coverage): allows scaling of the dwell time each participant dedicates to the AOI for the actual size of the AOI, averaging it across subjects and the twenty-four visual stimuli. This last indicator is particularly useful since it permits stating that the differences in time spent looking at a specific target are not driven by the dimension of the target.

- Average fixation duration: conveys the sum of average time of fixations (ms) per subject, divided by the number of subjects, averaged across the twenty-four visual stimuli.

\section{Data Analysis}

Descriptive statistics with mean, standard deviations, and percentages have been used to report the distribution of continuous parametric variables. The analysis of variance has been used to compare the distribution of outcome variables by AOIs, gender, and educational background. The probability level was set at .01, in order to account for multiple comparisons. Moreover, a logistic regression has been performed using the subjective judgement of product financial attractiveness as dependent variable while considering the trial average fixation duration as continuous independent variable and gender, and RRP score (low/high) and educational background (medicine/economics) as nominal independent variables.

\section{Results}

\section{Scan Path and Attention Allocation}

As revealed by Table 1, participants explore the documents following this sequence: Objectives (Top left) to RRP (Bottom left) to Costs and charges (Top right) to Past performance (Bottom right) $(p<.0001)$; afterwards, they look back to Risk scale in the $R R P$ area, then from the years 2014-2016, they look back to the years of the crisis (2007-2009), and finally, they look at the Disclaimer $(p<.0001)$. These data inform us that after an initial and first

\footnotetext{
${ }^{3}$ A scan path is defined as the sum of fixations and saccades where the formers are the period of time when the eye is stationary and gathers visual information and the latters are fast ballistic movements that redirect gaze.
} 
Table 1 Mean time to first fixation (ms) for the different AOIs (ANOVA; $p<.0001$ )

\begin{tabular}{lllr}
\hline AOI & Mean & Std. dev. & Std. err. \\
\hline Objectives & 923.5 & 2461.5 & 167.9 \\
RRP & 7276.2 & 8613.5 & 293.4 \\
Costs and charges & 7713.5 & 9413.5 & 321.6 \\
Past performance & 9637.0 & $10,795.8$ & 367.7 \\
Risk scale & $13,352.5$ & $11,336.8$ & 407.0 \\
2014-2016 & $15,368.9$ & $11,947.1$ & 414.7 \\
2007-2009 & $17,259.5$ & $13,096.7$ & 500.0 \\
Disclaimer & $20,413.1$ & $14,368.8$ & 594.6 \\
\hline
\end{tabular}

The sequence allows to track the subjects' average scan path

AOIs are listed in increasing order of entry time ( $\mathrm{ms}$ ) averaged across subjects and visual stimuli (first column), revealing the sequence by which they are visually scanned, i.e., the scan path. Standard deviation (second column) and Standard error (third column) are also displayed

exploration of the main four quadrants, the subjects look back to the other sources of information and they do so in the above-mentioned order.

As revealed by Table 2, (a) the Objectives' presentation is the source of information needing longer time to be processed, followed by the graph of the Past performance. Data reveal that the last years of the performance trends are scanned for a longer time than the three

Table 2 Attention allocation over the AOIs, reported through the main eye-tracking parameters

\begin{tabular}{llll}
\hline (a) Net dwell time (ms) & Mean & Std. Dev. & Std. Err. \\
Objectives & $15,221.3$ & 8995.4 & 306.0 \\
Past performance & 9258.5 & 7802.9 & 265.5 \\
RRP & 5781.8 & 4751.8 & 161.7 \\
Costs and charges & 5484.9 & 4343.8 & 147.8 \\
2014-2016 & 2655.7 & 2448.1 & 83.3 \\
2007-2009 & 1822.8 & 2318.3 & 78.9 \\
Risk scale & 1196.5 & 1644.2 & 55.9 \\
Disclaimer & 880.7 & 8403.5 & 28.6 \\
(b) Fixation count & Mean & Std. Dev. & Std. Err. \\
Objectives & 45.5 & 27.1 & 0.9 \\
Past performance & 25.1 & 21.4 & 0.7 \\
RRP & 18.2 & 14.7 & 0.5 \\
Costs and charges & 16.8 & 13.3 & 0.5 \\
2014-2016 & 6.4 & 6.0 & 0.2 \\
2007-2009 & 4.6 & 6.4 & 0.2 \\
Disclaimer & 3.9 & 5.5 & 0.2 \\
Risk scale & 2.9 & 2.5 & 0.1 \\
(c) Normalized dwell time (ms/pixel) & Mean & Std. err. \\
Objectives & $75,027.7$ & 1520.9 \\
2014-2016 & $64,296.7$ & $44,706.4$ & 2081.6 \\
Past performance & $45,305.2$ & $61,187.3$ & 1314.5 \\
2007-2009 & $42,911.4$ & $38,639.4$ & 1947.6 \\
RRP & $27,858.2$ & $57,246.5$ & 806.7 \\
Costs and charges & $26,397.0$ & $23,710.6$ & 728.8 \\
Risk scale & $24,322.3$ & 854.4 \\
Disclaimer & $15,740.5$ & 1298.0 \\
\hline
\end{tabular}

AOIs are listed in decreasing order of net dwell time (ms), fixation count, and normalized dwell time (ms/pixel), averaged across subjects and the visual stimuli (first column), revealing the ranking of attention allocation for each AOIs. Standard deviation (second column) and standard error (third column) are also displayed. Inter-AOIs differences were statistically significant at $p<.0001$, for all parameters 
initial years of the chart. The visual attention distribution pattern is confirmed by the variable FC displayed in panel (b), with the exception of the AOIs associated with the Risk scale which, from the second to last, becomes the last of the ranking, switching its position with the AOI referred to the Disclaimer. When taking into account the normalized dwell time (c), data indicate that Objectives are still the most relevant piece of information, immediately followed by the years of the crisis and later by the other part of the performance chart. This result confirms an important attractive role played by the last years of the chart during the early automatic visual exploration of the disclosure documents. The RRP and the Costs and charges' sections are observed more than the Risk scale.

\section{Gender-Differences in Attention Allocation and Perceived Attractiveness of the Investment}

No significant gender-related differences are found in the overall time taken to scan the whole document, on average. Moreover, no differences are found in the scan path, as both men and women explore the KIIDs according to the sequence described above. However, significant differences are detected with respect to attention distribution across different AOIs, as men spend more time looking at the Objectives than women (mean diff. NDW\% $=2.99, p<.01$ ), who seem to be more attracted by the section $R R P$ (mean diff. NDW\% $=2.33, p<.001$ ). Moreover, women spend more time looking at the section Costs and charges (mean diff. NDW\% $=2.25, p<.0002$ ) and men tend to spend more time looking at Past performance (mean diff NDW\% $=2.4, p<.05$ ). Table 3 presents mean, standard deviation, and standard error values of the relative measures of attention, across the AOIs, for men and women.

Women tend to have longer average fixation duration than men (mean diff: $11 \mathrm{~ms} ; p<.01$ ).

When looking into gender variability in the individual judgement of product financial attractiveness, we find that women tend to rate products as "Low" financially attractive more frequently than men (Odds ratio 2.3; 95\% C.I. 0.01-463.0).

To examine whether gender, RRP indicator, and visual attention, are independent factors of individual judgements of financial attractiveness, we dichotomized the dependent variable into "low" and "high" (attractive), after excluding intermediate judgments, and performed a binary logistic regression.

The analysis displayed in Table 4 shows the following associations:

Table 3 Attention allocation over each AOI (as percentage of the total scan time) in men and women

\begin{tabular}{|c|c|c|c|c|c|c|}
\hline \multirow[t]{2}{*}{ Net dwell time $\%$} & \multicolumn{3}{|c|}{ Men $(n=18)$} & \multicolumn{3}{|c|}{ Women $(n=18)$} \\
\hline & Mean & Std. Dev. & Std. Err. & Mean & Std. Dev. & Std. Err. \\
\hline Objectives & 41.2 & 14.9 & 0.7 & 38.3 & 16.8 & 0.9 \\
\hline Past performance & 25.9 & 14.2 & 0.7 & 23.5 & 16.1 & 0.8 \\
\hline $\mathrm{RRP}$ & 13.8 & 9 & 0.4 & 16.1 & 10.7 & 0.5 \\
\hline Costs and charges & 13.1 & 7.6 & 0.4 & 15.3 & 9.3 & 0.5 \\
\hline 2014-2016 & 7.3 & 5 & 0.2 & 8 & 7.4 & 0.4 \\
\hline $2007-2009$ & 5.4 & 5.3 & 0.3 & 3.7 & 3.8 & 0.2 \\
\hline Risk scale & 2.9 & 3.7 & 0.2 & 2.7 & 3.6 & 0.1 \\
\hline Disclaimer & 2.5 & 2.1 & 0.1 & 3.1 & 2.2 & 0.2 \\
\hline
\end{tabular}

AOIs are listed in decreasing order of net dwell time $\%$, averaged across subjects by gender and across the visual stimuli. Mean, standard deviation, and standard error are represented in the first, second, and third column of each panel, respectively 
Table 4 Results of binary logistic regression of possible independent factors of low attractiveness perception of financial products

\begin{tabular}{llll}
\hline \multicolumn{2}{l}{ Log. (relative odds) } & & \\
\hline & Coeff. $(\beta)$ & Std. Err. of $\beta$ & $p$-value \\
Intercept & 0.987 & 0.105 & $<.0001$ \\
Low RRP score & -1.825 & 0.081 & $<.0001$ \\
Gender: men & -0.428 & 0.082 & $<.0001$ \\
Medical background & -0.081 & 0.084 & .336 \\
Average fixation duration & 0.001 & 0.0002 & .0005 \\
R squared & 0.141 & & \\
\hline
\end{tabular}

The table shows that the probability of evaluating financial products as poorly attractive is directly related to average fixation duration and is lower in men

- A significant relationship between gender and "low attractive" judgements, revealing that women perceive financial products as poorly attractive, more frequently than men do ( $p<$ $.0001)$

- A significant relationship between RRP scores and "low attractive" judgements, revealing that a low RRP value drives subject's brains to perceive financial products as poorly attractive very rarely $(p<.0001)$

- A significant relationship between the average fixation duration and "low attractive" judgements, revealing that higher fixation durations, during product inspection, increase the probability of perceiving those financial products as poorly attractive $(p=.0005)$

- No relationship between subjects' background and financial attractiveness perception

\section{Discussion}

Disclosure is a commonly used regulatory tool, but whether documents are effective in reducing information asymmetry in financial markets increasing investors' protection remains an open question. The present research advances the knowledge on this issue, by applying a neuroscientific technique - the-eye tracking - to describe investor's visual attention mechanisms towards the information contained in a recently introduced disclosure document, the KIID. The collection and the analysis of oculomotor data related to the scan of financial information as a method to study the interaction between investors and the disclosure documents, and any gender-related variability, are completely new in the landscape of the studies on investors' protection and provide useful insights for the understanding of the investors' brain.

The analysis of the attention distribution across information sources revealed the tendency by men and women to develop different heuristics in approaching the financial document, with men more interested in two sections of the KIID - the Objectives and the Past performanceand women interested in the other two sections - RRP and Costs and charges. It appears that in order to formulate an immediate judgment on the attractiveness of the underlying financial product, men consider more salient the narrative description of the product and the graphical representation of the past performance. Oppositely, women consider the overview and the synthesis of the risks and the reward of the product and the associated costs as more salient cues. 
These gender differences detected for the visual attention allocation process are in the order of magnitude of milliseconds. Since such small differences surely occur beneath the threshold of conscious awareness, their influence on financial behaviour has for long supposed to be null, given the hypothesized subject's inability to integrate that information in the decision-making process. However, past research has proved that subliminal visual stimuli can capture attention and influence decision behaviour (Mulckhuyse et al. 2007; Van der Stigchel et al. 2009; Weichselbaum et al. 2014). Each basic unit of the brain, the neuron, can transmit up to $10^{15}$ different messages in one second; hence, considering that neurons are estimated to be 100 billion, the complexity of information processing is massive and therefore fractions of seconds become extremely important in any individual decision making process. Congruently, the statistically significant, though small, differences, detected in this study, deserve much attention.

We also sought to ascertain whether men and women display any differences in the evaluation of product financial attractiveness, and our results revealed that women, with respect to men, tend to evaluate more often products as poorly financially attractive. This behaviour can be linked to their visual exploratory strategy that allocates more attention to the sections RRP and Costs and charges, likely increasing the salience of these components and translating into a more conservative behaviour. Paying more attention to the description of the RRP and to the costs of the financial product might influence the less pronounced positive evaluation about its financial attractiveness. This finding provides a preliminary support to interpret the documented lower presence of risky behaviour among women (see the metaanalysis of 150 studies in psychology and sociology conducted by Byrnes et al. 1999), and suggests a new avenue for trying to explain the documented gender differences in financial behaviour (Barber and Odean 2001; Bucher-Koenen et al. 2016).

Generally, traditional economic models assume a uniform response from readers to details of a text while we highlighted the importance to consider the influence of gender on the exploration strategy of financial disclosure documents. Sex differences have been documented for a wide range of cognitive abilities (Nisbett et al. 2012; Reilly et al. 2015), in particular with respect to spatial and verbal abilities (Miller and Halpern 2013). However, neuroscientific researches on brain function development have investigated malleability in the phases of decision making processes, i.e., whether and to what extent the experience can alter individuals' skills, revealing that even small exogenous factors can be relevant. For instance, a metaanalysis conducted by Uttal (2013) highlighted that men and women can improve spatial skills equally well with training; congruently, the longitudinal analysis conducted by Lachance and Mazzocco (2006) underscored the absence of any consistent gender difference in math and spatial skills among children in primary school. In the literature, there is neither any clear evidence on the existence of gender differences nor any information about the association between the observed gap and any inherent or culturally influenced sex differences; However, this topic is becoming increasingly interesting given its practical implications for policy makers. In this study, we focused on visual-spatial attention; hence, any gender-related difference in visual spatial information processing, as a product of different spatial training in schools or different experiences in out-of-school activities such as video games (Feng et al. 2007; Hyde 2014), could contribute to the differences in the visual search strategy detected in our exploratory study. In support to this interpretation, we found, in our sample, that women played video games less frequently than men. Hence, this different exposure to visual spatial tasks, during growth, could have influenced the observed subtle gender differences in visual performances. Eventually, we should sound a note of caution with regard to the overall findings of this study since many researchers are underlining the need not to perpetuate 
stereotypes about men and women, by emphasizing small gender differences instead of underpinning that the within-gender variance is greater than the between-gender variance (Hyde 2014).

This study represents the first investigation of gender-related neurophysiological mechanisms of information processing in financial disclosure documents. A focus on the "ergonomics" of the documents, based on how individual's brain processes of financial information, could help to improve the design of financial disclosure documents, detecting how to modulate attention allocation and financial decision-making, raising the level of investors' protection. We argue that the study of the neurophysiological mechanisms should represent a new line of research in the field of investors' protection: in fact, such researches could provide useful information to be embedded in the world-wide ongoing regulatory developments (MIFID II, CRM 2) that aim at increasing transparency requirements. As scholars, we are interested also in operative applications of these findings to protect investors' interests. By highlighting differences and similarities in men and women information processing, we suggest regulators and supervisors to monitor sellers and marketers' behaviours when they interact with customers through information disclosure documents. In this sense, given women's attraction towards the sections RRP and Costs and charges, they might be prompted by financial advisors to pay more attention towards the other two sections of the documents. On the contrary, male customers, who seem to be more interested in the Objective and Past performance sections, could be invited to drive more attention to the other sections of the document. This could help to foster an exploratory behaviour where equal attention is allocated to all the sources of information conveyed through the document, which are retained by regulators as equally important for investors to take informed decisions.

In addition, our findings might have some policy implications as highlighting the importance to introduce financial educational programmes to train people (especially women) to develop spatial reasoning. A similar growth of visual spatial skills in both men and women would increase investor's protection, also avoiding market segmentation. Moreover, if different strategies of information processing are associated with a different product evaluation perception (Graham et al. 2002), regulators and supervisors might be interested in drafting documents that might facilitate women participations either in the stock markets, given that more gender variability in the financial sectors is supposed to reduce financial instability (van Staveren 2014).

This study is not without limitations. A first weakness of the research is the measure of subjects' product evaluation that is based on the declared attractiveness perception. The task of rating the attractiveness has been introduced in order to enhance subjects' motivation and collect data on their first impression, to study the link between attention and behaviour. Anyway, this measure is based on a self-report method rather than on an actual decision, and researchers have underlined the importance of considering neural correlates of financial decision-making of subjects who use their own financial resources in real financial market (Raggetti et al. 2017). The decision-making process consists of several phases such as information acquisition and processing, attributes weighting, activation of the working memory, activation of long-term memory, integration of sensory, mnesic and emotional information, process monitoring and response inhibition, and output selection, action. The present experimental design only permits to (i) explore the visual attention mechanisms of processing financial information and (ii) detect subjects' evaluation of the products. Anyway, several variables could affect the link between subject's attention and his/her judgment on the attractiveness of the product, such as the level of financial literacy, the understanding of the 
information, the risk attitude, and experience. We attempted to reduce the influence of some of these factors, controlling them through the inclusion and exclusion criteria for the sample selection and standardizing the features of the visual stimuli. Thus, our study cannot be considered conclusive but rather exploratory. Finally, we only considered the eye-tracking metrics of fixations, overlooking information about emotional reactions that are offered by pupillometry (the measurement of pupil diameter dynamics).

This research provides the basis for several further developments which could consider the role of other individual-level characteristics as personality traits, overconfidence, experience, risk attitude, numeracy, financial literacy (Hauff et al. 2020), graph literacy (Okan et al. 2016) in modulating information processing, and product evaluations. Moreover, future studies might explore other phases of the decision-making rather than visual attention and observe behaviour related to actual choice. In addition, these findings could be integrated with pupillometry and electroencephalogram (EEG) data, which inform about temporal resolution of the decision-making process. Finally, the role played by other contextual stimuli, as music or environmental positive/negative cues, on the attention distribution pattern and on the consequent evaluation of product, could be explored.

Funding Open access funding provided by Università degli Studi di Roma Tor Vergata within the CRUICARE Agreement. The research belongs to the project NEUROFIN funded by "Consolidate the Foundations" of the University of Rome Tor Vergata.

Open Access This article is licensed under a Creative Commons Attribution 4.0 International License, which permits use, sharing, adaptation, distribution and reproduction in any medium or format, as long as you give appropriate credit to the original author(s) and the source, provide a link to the Creative Commons licence, and indicate if changes were made. The images or other third party material in this article are included in the article's Creative Commons licence, unless indicated otherwise in a credit line to the material. If material is not included in the article's Creative Commons licence and your intended use is not permitted by statutory regulation or exceeds the permitted use, you will need to obtain permission directly from the copyright holder. To view a copy of this licence, visit http://creativecommons.org/licenses/by/4.0/.

\section{References}

Almenberg, J., \& Dreber, A. (2015). Gender, stock market participation and financial literacy. Economics Letters, $137(C), 140-142$.

Ashby, N. J. S., Johnson, J. G., Krajbich, I., \& Wedel, M. (2016). Applications and innovations of eye-movement research in judgment and decision making. Journal of Behavioral Decision Making, 29, 96-102.

Bajtelsmit, V. L., \& VanDerhei, J. L. (1997). Risk aversion and pension investment choices. In M. S. Gordon, O. S. Mitchell, \& M. M. Twinney (Eds.), Positioning pensions for the twenty-first century (pp. 45-66). Philadelphia, PA: University of Pennsylvania Press.

Barber, B. M., \& Odean, T. (2001). Boys will be boys: Gender, overconfidence, and common stock investment. The Quarterly Journal of Economics, 116, 261-292.

Bauer, J. M., \& Reisch, L. A. (2019). Behavioural insights and (un)healthy dietary choices: A review of current evidence. Journal of Consumer Policy, 42, 3-45.

Boggio, C., Moscarola, F. C., \& Gallice, A. (2020). What is good for the goose is good for the gander?: How gender-specific conceptual frames affect financial participation and decision-making. Economics of Education Review, 75, 101952.

Buchanan, B. G. (2016). Securitization: A financing vehicle for all seasons? Journal of Business Ethics, 138, 559-577.

Bucher-Koenen, T., Lusardi, A., Alessie, R. J. M., \& van Rooij, M. C. J. (2016). How financially literate are women? An overview and new insights. The Journal of Consumer Affairs, 51, 255-283.

Byrnes, J. P., Miller, D. C., \& Schafer, W. D. (1999). Gender differences in risk taking: A meta-analysis. Psychological Bulletin, 125, 367-383. 
Ceravolo, M., Farina, V., Fattobene, L., Leonelli, L., \& Raggetti, G. (2019). Presentational format and financial consumers' behaviour: An eye-tracking study. International Journal of Bank Marketing, 37, 821-837.

Chowdhury, R. M. M. I. (2019). The moral foundations of consumer ethics. Journal of Business Ethics, 158, 585-601.

Cueva, C., \& Rustichini, A. (2015). Is financial instability male-driven? Gender and cognitive skills in experimental asset markets. Journal of Economic Behavior and Organization, 119, 330-344.

Dema-Moreno, S. (2009). Behind the negotiations: Financial decision-making processes in Spanish dual-income couples. Feminist Economics, 15(1), 27-56.

Durkin, T. A., \& Elliehausen, G. (2011). Truth in lending: Theory, history, and a way forward. Oxford: Oxford University Press.

Feng, J., Spence, I., \& Pratt, J. (2007). Playing an action video game reduces gender differences in spatial cognition. Psychological Science, 18, 850-855.

Fine, C. (2012). Explaining, or sustaining, the status quo? The potentially self-fulfilling effects of 'hardwired' accounts of sex differences. Neuroethics, 5, 285-294.

Fisher, P. J. (2010). Gender differences in personal saving behaviors. Journal of Financial Counseling and Planning, 21, 14-24.

Graham, D. J., \& Jeffery, R. W. (2012). Location, location, location: Eye-tracking evidence that consumers preferentially view prominently positioned nutrition information. Journal of the American Dietetic Association, 111, 1704-1711.

Graham, J. R., Harvey, C. R., \& Huang, H. (2009). Investor competence, trading frequency, and home bias. Management Science, 55, 1094-1106.

Graham, J., Stendardi, E., Myers, J., \& Graham, M. (2002). Gender differences in investment strategies: An information processing perspective. International Journal of Bank Marketing, 20, 17-26.

Hariharan, G., Chapman, K. S., \& Domian, D. L. (2000). Risk tolerance and asset allocation for investors nearing retirement. Financial Services Review, 9, 159-170.

Hauff, J. C., Carlander, A., Gärling, T., \& Nicolini, G. (2020). Retirement financial behaviour: How important is being financially literate? Journal of Consumer Policy, 43, 543-564.

Hayhoe, C. R., Leach, L. J., Turner, P. R., Bruin, M. J., \& Lawrence, F. C. (2000). Differences in spending habits and credit use of college students. Journal of Consumer Affairs, 34, 113-133.

Hogarth, J. M., \& Merry, E. A. (2011). Designing disclosures to inform consumer financial decision making: Lessons learned from consumer testing (Federal Reserve Bulletin, August, 97, 1-27). Federal Reserve.

Holmqvist, K., Nyström, M., Andersson, R., Dewhurst, R., Halszka, J., \& van de Weijer, J. (2011). Eye tracking: A comprehensive guide to methods and measures. Oxford: Oxford University Press.

Hung, A. A., Gong, M., \& Burke, J. (2015). Effective disclosures in financial decision making. (Issue No. RR1270-DOL). Santa Monica, CA: RAND Corporation.

Hyde, J. S. (2014). Gender similarities and differences. Annual Review of Psychology, 65, 373-398.

Jianakoplos, N. A., \& Bernasek, A. (1998). Are women more risk averse? Economic Inquiry, 36, 620-630.

Lachance, J. A., \& Mazzocco, M. M. (2006). A longitudinal analysis of sex differences in math and spatial skills in primary school age children. Learning and Individual Differences, 16, 195-216.

Lacko, J. M., \& Pappalardo, J. K. (2007). Improving consumer mortgage disclosures-An empirical assessment of current and prototype disclosure forms. Washington, DC: Federal Trade Commission, Bureau of Economics.

Lacko, J. M., \& Pappalardo, J. K. (2010). The failure and promise of mandated consumer mortgage disclosures: Evidence from qualitative interviews and a controlled experiment with mortgage borrowers. American Economic Review, 100, 516-521.

London, A., Benhar, I., \& Schwartz, M. (2013). The retina as a window to the brain-From eye research to CNS disorders. Nature Reviews Neurology, 9, 44-53.

Lusardi, A., \& Mitchell, O. S. (2008). Planning and financial literacy: How do women fare? American Economic Review, 98, 413-417.

Lyons, A. C., Neelakantan, U., \& Scherpf, E., (2008). Gender and marital differences in wealth and investment decisions: Implications for researchers, financial professionals, and educators (Issue No. 2008-WP-02, Working Paper). Indiana State University, Scott College of Business, Networks Financial Institute.

Marette, S., Nabec, L., \& Durieux, F. (2019). Improving nutritional quality of consumers' food purchases with traffic-lights labels: An experimental analysis. Journal of Consumer Policy, 42, 377-395.

McNair, S., Summers, B., Bruine de Bruin, W., \& Ranyard, R. (2016). Individual-level factors predicting consumer financial behavior at a time of high pressure. Personality and Individual Differences, 99, 211-216.

Meyers-Levy, J. (1989). Gender differences in information processing: A selectivity interpretation. In P. Cafferata \& A. Tybout (Eds.), Cognitive and Affective Responses to Advertising (pp. 219-260). Lexington: Lexington Press.

Miendlarzewska, E. A., Kometer, M., \& Preuschoff, K. (2017). Neurofinance. Organizational Research Methods, 22, 196-222. 
Miller, D. I., \& Halpern, D. F. (2013). The new science of cognitive sex differences. Trends in Cognitive Sciences, 18, 37-45.

Mulckhuyse, M., Talsma, D., \& Theeuwes, J. (2007). Grabbing attention without knowing: Automatic capture of attention by subliminal spatial cues. Visual Cognition, 15, 779-788.

Ní Choisdealbha, Á., \& Lunn, P. D. (2020). Green and simple: Disclosures on eco-labels interact with situational constraints in consumer choice. Journal of Consumer Policy, 43, 699-722.

Nisbett, R. E., Aronson, J., Blair, C., Dickens, W., Flynn, J., Halpern, D. F., et al. (2012). Intelligence: New findings and theoretical developments. American Psychologist, 67, 130-159.

Noton, D., \& Stark, L. (1971). Scanpaths in saccadic eye movements while viewing and recognizing patterns. Vision Research, 11(9), 929-942.

O’Connell, B., Walden, S., \& Pohlmann, A. (2011). Marketing and neuroscience: What drives customer decisions? (American Marketing Association White Paper). Chicago, IL: American Marketing Association.

Oehler, A., \& Wendt, S. (2016). Good consumer information: The information paradigm at its (dead) end? Journal of Consumer Policy, 40(2), 179-191.

Oehler, A., Höfer, A., \& Wendt, S. (2014). Do key investor information documents enhance retail investors' understanding of financial products? Empirical evidence. Journal of Financial Regulation and Compliance, $22,115-127$.

Okan, Y., Galesic, M., \& Garcia-Retamero, R. (2016). How people with low and high graph literacy process health graphs: Evidence from eye-tracking. Journal of Behavioral Decision Making, 29, 271-294.

Ölander, F., \& Thøgersen, J. (2014). Informing versus nudging in environmental policy. Journal of Consumer Policy, 37, 341-356.

Olsen, R., \& Cox, C. (2001). The influence of gender on the perception and response to investment risk: The case of professional investors. Journal of Psychology and Financial Markets, 2, 29-36.

Orquin, J. L. (2014). A Brunswik lens model of consumer health judgments of packaged foods. Journal of Consumer Behaviour, 13, 270-281.

Poddar, A., Ellis, M., \& C., \& Ozcan, T. (2014). Imperfect recall: The impact of composite spending information disclosure on credit card spending. Journal of Consumer Policy, 38, 93-104.

Raggetti, G., Ceravolo, M. G., Fattobene, L., \& Di Dio, C. (2017). Neural correlates of direct access trading in a real stock market: An fMRI investigation. Frontiers in Neuroscience, 11, 536.

Reilly, D., Neumann, D. L., \& Andrews, G. (2015). Sex differences in mathematics and science: A meta-analysis of National Assessment of Educational Progress assessments. Journal of Educational Psychology, 107, 645662 .

Schoen, E. J. (2017). The 2007-2009 financial crisis: An erosion of ethics: A case study. Journal of Business Ethics, 146, 805-830.

SEC. (2007). Enhanced disclosure and new prospectus delivery option for registered open-end management investment companies (Issue No. 33-8861, IC-28064). Washington, DC: Securities and Exchange Commission.

SEC. (2014). IM Guidance Update: Guidance regarding mutual fund enhanced disclosure (Issue No. 2014-08). Washington, DC: Securities and Exchange Commission.

Soll, J. B., Keeney, R. L., \& Larrick, R. P. (2013). Consumer misunderstanding of credit card use, payments, and debt: Causes and solutions. Journal of Public Policy \& Marketing, 32, 66-81.

Strömbäck, C., Lind, T., Skagerlund, K., Västfjäll, D., \& Tinghög, G. (2017). Does self-control predict financial behavior and financial well-being? Journal of Behavioral and Experimental Finance, 14, 30-38.

Uttal, D. H., Meadow, N. G., Tipton, E., Hand, L. L., Alden, A. R., Warren, C., et al. (2013). The malleability of spatial skills: A meta-analysis of training studies. Psychological Bulletin, 139, 352-402.

Van der Stigchel, S., Mulckhuyse, M., \& Theeuwes, J. (2009). Eye cannot see it: The interference of subliminal distractors on saccade metrics. Vision Research, 49(16), 2104-2109.

van Staveren, I. P. (2014). The Lehman sisters hypothesis. Cambridge Journal of Economics, 38, 995-1014.

Vanguard Retirement Centre Research. (2011). The Great Recession and 401(k) plan participant behaviour. Valley Forge, PA: Vanguard Group.

Vraga, E. K., Bode, L., \& Troller-Renfree, S. (2016). Beyond self-reports: Using eye tracking to measure topic and style differences in attention to social media content. Communication Methods and Measures, 10, 149-164.

Walther, T. (2015). Key investor documents and their consequences on investor behaviour. Journal of Business Economics, 85, 129-156.

Wealth, B. (2011). Understanding the female economy: The role of gender in financial decision making and succession planning for the next generation. London: Barclays Wealth and Ledbury Research.

Weichselbaum, H., Fuchs, I., \& Ansorge, U. (2014). Oculomotor capture by supraliminal and subliminal onset singletons: The role of contrast polarity. Vision Research, 100, 1-7.

Yilmazer, T., \& Lyons, A. C. (2010). Marriage and the allocation of assets in women's defined contribution plans. Journal of Family and Economic Issues, 31, 121-137. 
Zhou, L., Zhang, Y.-Y., Wang, Z.-J., Rao, L.-L., Wang, W., Li, S., et al. (2016). A scanpath analysis of the risky decision-making process. Journal of Behavioral Decision Making, 29, 169-182.

Zubair Tauni, M., Yousaf, S., \& Ahsan, T. (2020). Investor-advisor Big Five personality similarity and stock trading performance. Journal of Business Research, 109, 49-63.

\section{Cases}

\section{European Union}

Mortgage Credit Directive 2014/17/EU

\section{Legislation}

\section{United States of America}

Credit Card Accountability Responsibility and Disclosure (CARD) Act 2009

Publisher's Note Springer Nature remains neutral with regard to jurisdictional claims in published maps and institutional affiliations.

\section{Affiliations}

\section{G. Ceravolo ${ }^{1} \cdot$ V. Farina ${ }^{2} \cdot$ L. Fattobene $^{2} \cdot$ L. Leonelli $^{2} \cdot$ G. Raggetti ${ }^{3}$}

\section{G. Ceravolo}

m.g.ceravolo@univpm.it

V. Farina

vincenzo.farina@uniroma2.it

L. Leonelli

leonelli@uniroma2.it

G. Raggetti

g.raggetti@univpm.it

Department of Experimental and Clinical Medicine, University Politecnica Marche, Via Tronto 10/a, 60015 Ancona, Italy

2 Department of Management and Law, University of Rome 'Tor Vergata', Via Columbia 2, 00133 Rome, Italy

3 BrainLine Association, Via Tronto 10/a, 60015 Ancona, Italy 